\title{
SEXUALIDADE NA SALA DE AULA: TECENDO APRENDIZAGENS A PARTIR DE UM ARTEFATO PEDAGÓGICO
}

\author{
Benícia Oliveira da Silva \\ Universidade Federal do Rio Grande \\ Paula Regina Costa Ribeiro \\ Universidade Federal do Rio Grande
}

\begin{abstract}
Resumo: Neste artigo, discutimos a seção Sexo da revista Capricho como um artefato cultural. Em nossas discussões, compreendemos que esse artefato constitui-se em uma pedagogia cultural que produz e divulga significados acerca da temática sexualidade, operando não apenas como fonte de informação ou entretenimento. Esse artefato, além de possibilitar a discussão de questões como sistemas genitais, métodos contraceptivos, Aids e DST, que já estão presentes nos currículos escolares e nos Parâmetros Curriculares Nacionais (PCN), promove a inclusão de temas acerca de anseios, medos, prazeres, comportamento, gênero e corpo que nem sempre são abordados nos currículos, problematizando, assim, diferentes representações e significados atribuídos à sexualidade e que circulam em nossa sociedade. Palavras-chave: artefatos culturais; sexualidade; seção Sexo.
\end{abstract}

\section{Entrelaçamentos iniciais}

O presente artigo tem como objetivo discutir a revista Capricho - em especial a seção Sexo - não apenas como fonte de informação ou entretenimento, mas como um artefato em que estão presentes determinadas formas de pedagogias que possibilitam o uso da Revista como uma ferramenta na prática pedagógica de ensino e aprendizagem. ${ }^{1}$

Nesse sentido, a partir do referencial teórico dos Estudos Culturais e de algumas proposições de Michel Foucault, percebemos a mídia - e particularmente a revista Capricho - como uma espécie de manual de comportamento que ensina a suas leitoras adolescentes determinados modos de ser. Os Estudos Culturais têm suas análises centradas em dimensões

Copyright ( 2011 by Revista Estudos Feministas.

${ }^{1}$ Alguns dados deste trabalho foram apresentados no VI Congresso Internacional de Educação e no VII Encontro Nacional de Pesquisa em Educação em Ciências - Enpec, ambos no ano de 2009. 
culturais, compreendendo todas as práticas, produtos e espaços culturais como produtores de significados. Dessa forma, é possível entender as instâncias culturais - mídia, família, instituições religiosas, bem como a escola - como educativas, isto é, possuem pedagogias, "também ensinam alguma coisa".

A revista Capricho, ${ }^{3}$ criada em 1952, é uma revista quinzenal que tem como públicoalvo meninas adolescentes. Seu sucesso e liderança no mercado identificam-na como um artefato de grande circulação entre esse público. Segundo o site da editora responsável pela publicação da Revista, a "Capricho é líder absoluta na comunicação com as garotas brasileiras [...]. Hoje são mais de 2,2 milhões de leitoras por edição". ${ }^{4}$

Desde junho de $2006,{ }^{5}$ a seção Sexo caracteriza-se como um espaço em que são discutidas questões relacionadas a momentos antes, durante e depois da relação sexual. Essa seção é produzida com a participação das leitoras; no site ${ }^{6}$ da Revista as adolescentes podem se inscrever e participar com seus comentários ou opinar em enquetes sobre questões acerca da temática que intitula a seção.

Nesse contexto, identificou-se a revista Capricho - seção Sexo - como um artefato cultural de grande circulação e alcance entre as adolescentes no qual é possível evidenciar múltiplos discursos acerca da temática sexualidade.

\section{Tecendo significados: a perspectiva teórica}

As reflexões aqui realizadas fundamentam-se nos Estudos Culturais, em suas vertentes pós-estruturalistas. A partir desse campo teórico, entendemos as sexualidades e a adolescência ${ }^{7}$ como construções culturais produzidas nos acontecimentos históricos e culturais das experiências das pessoas.

Os Estudos Culturais entendem as práticas culturais como produtoras de significados. A partir disso, buscam desconstruir os binarismos e as diferenças entre os diferentes tipos de culturas. Segundo Stuart Hall, ${ }^{8}$ a cultura "tem a ver com a produção e o intercâmbio dos significados - o 'dar e o receber de significados' - entre os membros de uma sociedade ou grupo". Para que haja a produção e o intercâmbio entre os significados, é preciso que esses tenham certo sentido. Assim sendo, a linguagem tem fundamental importância, pois é a partir dela que os significados serão compartilhados. A linguagem produz os significados, promovendo o intercâmbio entre os indivíduos de uma rede social, através de signos, sinais, símbolos de conhecimento comum, representados por palavras, sons, imagens e outras coisas que de alguma forma vão representar, igualmente, para as pessoas de uma mesma rede, algum significado.

\footnotetext{
2 Tomaz Tadeu da SILVA, 2009, p. 139.

3 CAPRICHO, 2009.

${ }^{4}$ PUBLIABRIL, 2011.

${ }^{5}$ CAPRICHO, 2009. O acesso ao link < http://app.arquivo.abril.com.br/texto_integral_abril/pesquisaConteudo.do> só era permitido a assinantes da revista. Nele, era possível ter acesso a pubulicaçõē de edições da revista desde 1999. A partir dessas edições foi realizada a pesquisa sobre a data de início da seção Sexo. No entanto, no ano de 2011 o site da revista foi modificado, não oferecendo mais essa opção.

${ }^{6}$ Disponível em: <http://capricho.abril.com.br/home/>.

${ }^{7}$ Neste trabalho, tomamos o entendimento de adolescência a partir de Raquel Pereira QUADRADO, 2006, p. 28, que entende a adolescência como "uma construção que se dá a partir dos discursos de diversos campos [...] e de diversas pedagogias culturais [...] que, ao representarem a adolescência, estão indo além de dizer ou mostrar o que é ser adolescente, estão ativamente produzindo essa etapa da vida e atuando, também, na produção de identidades".

${ }^{8}$ Stuart HALL, 1997, p. 2.
} 
Para Hall, o significado também é produzido "através de meios; especialmente, nestes dias, nos modernos meios de massa, os meios de comunicação global, por tecnologias complexas, que circulam significados entre diferentes culturas". 9

Nesse sentido, consideramos os artefatos culturais - produções e práticas (peças publicitárias, músicas, comunidades da internet, videoclipes, charges, revistas, jornais, programas televisivos e radiofônicos) construídas culturalmente - como produtores, reprodutores e divulgadores de significados.

Dessa forma, identificamos a seção Sexo da revista Capricho como um artefato cultural que promove a produção e a circulação de significados acerca da temática sexualidade, mas como uma ferramenta para o ensino, a qual, ao propiciar a abordagem de assuntos como cuidados com o corpo, gravidez não planejada, relacionamentos, DST etc., também ensina significados sobre essas questões, possibilitando, assim, problematizações acerca do tema, ou seja, repensar o que tem sido ensinado sobre sexualidade.

Nesse contexto, a partir dos pressupostos dos Estudos Culturais, é possível compreender que "outras instâncias culturais também são pedagógicas, também têm uma 'pedagogia', também ensinam alguma coisa", ${ }^{10}$ isto é, os processos pedagógicos não se limitam apenas ao espaço escolar, como a educação formal, mas também a outras instâncias como a família, a instituição religiosa, a internet e a própria mídia.

\section{Parâmetros Curriculares Nacionais como artefato cultural: fios da sexualidade que engendram essa teia pedagógica}

Assim como a revista Capricho, os Parâmetros Curriculares Nacionais (PCN) também podem ser considerados um artefato cultural, pois eles também são resultado de uma construção social. Nesse artefato, assim como nos livros didáticos, a sexualidade é abordada a partir de discursos ${ }^{11}$ biologicistas constituídos por pedagogias que vêm funcionando como estratégias ${ }^{12}$ para o controle dos comportamentos dos indivíduos - "use camisinha", "não transe", "cuide de seu corpo", "conheça os métodos anticoncepcionais", "Aids mata"...

Dessa forma, ao mencionar apenas o discurso biológico para falar sobre sexualidade, legitima-se o conhecimento científico como único e verdadeiro, resumindo o tema aos sistemas genitais, universalizando os sujeitos como se eles compartilhassem os mesmos atributos biológicos independentemente de seus contextos históricos e culturais.

Nos PCN, a sexualidade é abordada como um dado natural e inerente sobre o qual os sujeitos precisam ser informados. Sua própria inserção ${ }^{13}$ no âmbito curricular foi motivada pelo alto índice de gravidez entre adolescentes, bem como pela proliferação do vírus da imunodeficiência adquirida (HIV) e de outras doenças sexualmente transmissíveis, dando origem ao tema transversal Orientação Sexual.

Desse modo, a partir da inserção do tema transversal Orientação Sexual, institui-se não apenas um meio de incluir a temática sexualidade no âmbito escolar, mas também

\footnotetext{
9 HALL, 1997, p. 3, grifo nosso.

10 SILVA, 2009, p. 139.

${ }^{11} \mathrm{Na}$ perspectiva foucaultiana, os discursos não descrevem simplesmente objetos, mas produzem os objetos sobre os quais falam. O importante não é defrontarmos o discurso e o objeto ao qual se refere, mas examinarmos quais são seus efeitos de verdade, isto é, determinar como são tomados como verdades. 12 Utilizo "estratégia", num sentido foucaultiano, como um mecanismo de poder que tem como finalidade o controle da ação dos outros.

${ }^{13}$ Helena ALTMANN, 2001.
} 
um dispositivo ${ }^{14}$ de controle sobre as formas de os sujeitos viverem suas sexualidades, reduzindo-a a uma disciplina sobre o corpo que atua como um mecanismo de regulamentação da sexualidade.

Nessa direção, as práticas escolares passam a falar sobre sexualidade a partir de discursos médicos e biologicistas, no intuito de regular a forma como os indivíduos e a população devem viver suas sexualidades. Assim, a partir das proposições de Michel Foucault, a educação sexual pode ser entendida como um mecanismo de disciplinamento e de regulamentação da vida humana que pretende a preservação do corpo social. Para o autor, "a sexualidade está exatamente na encruzilhada do corpo e da população"15 e é sobre esse corpo e essa população que se aplicam as técnicas de poder ${ }^{16}$ disciplinar e a biopolítica:

[...] a disciplina tenta reger a multiplicidade dos homens na medida em que essa multiplicidade pode e deve redundar em corpos individuais que devem ser vigiados, treinados, utilizados, eventualmente punidos [...] Logo, depois de uma primeira tomada de poder sobre o corpo que se faz consoante o modo de individualização, temos uma segunda tomada de poder que, por sua vez, não é individualizante, mas que é massificante [...] que se faz em direção não do homem-corpo, mas do homem espécie [...] algo que já não é uma anátomo-política do corpo humano, mas que eu chamaria de uma "biopolítica" da espécie humana."

Nesse sentido, os incitamentos acerca dos cuidados preventivos contra a gravidez não planejada na adolescência, a Aids e outras DST presentes nos PCN e nos livros didáticos podem ser identificados como mecanismos da biopolítica atuando.

Não diferente dos artefatos mencionados no parágrafo anterior, a revista Capricho também regulamenta a forma de suas leitoras viverem suas sexualidades e tampouco escapa aos discursos biologicistas ao falar sobre o tema. Nesse artefato, especificamente na seção Sexo, na qual são discutidas questões relacionadas a momentos antes, durante e depois da relação sexual, a sexualidade é produzida a partir de significados e representações de determinados campos científicos, como o da Medicina, o da Biologia, o da Psicologia e o da Psiquiatria. Dessa forma, percebe-se que esses campos de saber vêm sendo privilegiados na determinação dos significados vinculados a essas questões na sociedade contemporânea.

A priori, a revista Capricho pode parecer apenas mais uma prática de replicação dos discursos cientificistas, porém esse artefato diferencia-se dos demais (PCN e livros didáticos) por constituir um espaço em que as adolescentes podem identificar-se com determinado grupo social de determinada cultura, ${ }^{18}$ possibilitando que se posicionem e compartilhem experiências relacionadas as suas sexualidades.

\footnotetext{
14 "O dispositivo é a rede de relações que podem ser estabelecidas entre elementos heterogêneos: discursos, instituições, arquiteturas, regramentos, leis, medidas administrativas, enunciados científicos [...] O dispositivo estabelece a natureza do nexo que pode existir entre esses elementos heterogêneos. Por exemplo, o discurso pode aparecer como programa de uma instituição, como um elemento que pode justificar ou ocultar uma prática, ou funcionar como uma interpretação a posteriori dessa prática, oferecer-lhe um campo novo de racionalidade" (Edgardo CASTRO, 2009, p. 124).

${ }^{15}$ Michel FOUCAULT, 2005, p. 300.

${ }^{16}$ Foucault não falou de poder como algo unitário, mas sim em relações de poder, as quais não representam algo negativo, ao contrário, são produtivas e se dão numa ação sobre a ação do outro.

17 FOUCAULT, 2005, p. 289.

${ }^{18}$ Aqui, entendemos cultura, a partir de Silva, como uma "forma global de vida ou como experiência vivida de um grupo social" (SILVA, 2009, p. 133).
}

524 Estudos Feministas, Florianópolis, 19(2): 521-533, maio-agosto/201 1 


\section{Entrelaçando fios: a utilização das revistas como artefatos culturais nas salas de aula}

A mídia, assim como outras instâncias, tem desempenhado um papel pedagógico cultural, atuando como um meio de produção e divulgação de discursos acerca da sexualidade adolescente, ao abordar essas temáticas - corpos, gêneros e sexualidades como problemas de saúde sexual e reprodutiva, tratando-as a partir dos discursos médico e biológico sobre o funcionamento do corpo e das doenças para prescrever um autocuidado e, através dele, controlar o corpo e a sexualidade. Segundo Rosa Fischer,

[...] é possível imaginar que a mídia funcionaria, em nossa época, como uma espécie de lugar de superposição de "verdades", justamente por ter se transformado em um local privilegiado de produção, veiculação e circulação de enunciados de múltiplas fontes, sejam eles diretamente criados a partir de outras formações, sejam eles gerados nos próprios meios. Uma de suas características principais é que, nela, por uma razão basicamente do alcance das tecnologias investidas nesse campo, qualquer discurso, materializado em entrevista de TV, cena de telenovela, reportagem de jornal, coluna de revista feminina, é passível de ter sua força de efeito ampliada, de uma forma radicalmente diferente do que sucede a um discurso que, por exemplo, opera através das páginas de um livro didático ou de um regulamento disciplinar escolar.

A citação de Fischer leva-nos a pensar por que as aprendizagens escolares não têm - mesmo alcance e a mesma significação para os/as alunos/as como os enunciados produzidos e gerados pela mídia. Talvez, ao pensarmos no currículo escolar, encontremos algumas razões que justifiquem a escola não "ter sua força de efeito ampliada". Analisar o currículo sob a ótica pós-estruturalista possibilita pensá-lo como prática cultural e de significação. Para Silva,

[...] o currículo não pode ser visto simplesmente como um espaço de transmissão de conhecimentos. O currículo está centralmente envolvido naquilo que somos, naquilo que nos tornamos, naquilo que nos tornaremos. O currículo produz, o currículo nos produz. $^{20}$

Nessa direção, é nas relações sociais que se constroem conhecimentos e saberes. No entanto, o currículo escolar parece ignorar os/as alunos/as como sujeitos sociais e históricos, constituídos/as dentro de determinada cultura, preocupando-se apenas em instituir padrões, normas, habilidades, valores e outros condicionantes; o currículo escolar acredita que de fato esteja efetivando a formação de bons cidadãos.

Segundo Jurjo Santomé, "uma das finalidades fundamentais de toda a intervenção curricular é a de preparar os/as alunos/as para serem cidadãos/ãs ativos e críticos". ${ }^{21}$ Porém, os processos curriculares atualmente elaborados têm como autores/as professores/ as e profissionais formados/as a partir de um modelo tradicional de educação, no qual se tem como objetivo a transmissão e a reprodução de conteúdos, o que conseguintemente afasta o projeto curricular de sua meta. Essa tradição também pode justificar a presença hegemônica de certas culturas, como a cor branca, a religião católica, a heterossexualidade e o próprio conteúdo do livro didático ser concebido como único possível e pensável. No âmbito da sexualidade, o currículo escolar não escapa às tradições. O que vemos é uma padronização do modo de vivê-la e senti-la, reduzindo os sujeitos a uma especificidade

${ }^{19}$ Rosa Maria Bueno FISCHER, 1996, p. 123.

${ }^{20}$ SILVA, 2006, p. 27.

${ }^{21}$ Jurjo Torres SANTOMÉ, 2008, p. 159. 
singular que nega suas historicidades e os descreve e produz como universalmente iguais. Para Guacira Louro, ${ }^{22}$ o currículo e as práticas escolares vêm sendo sustentados por um entendimento singular de sexualidade, mesmo admitindo a existência de muitas formas de vivê-la; "é consenso que a instituição escolar tem obrigação de nortear suas ações por um padrão [...] afastar-se desse padrão significa buscar o desvio, sair do centro". Dessa forma, a sexualidade ainda é vista como um problema a ser abordado em nossas salas de aula, pois a realidade escolar é de uma multiplicidade de sujeitos com características singulares, tornando problemática a tentativa de qualquer tipo de enquadramento. Talvez por isso falar sobre sexualidade não seja uma tarefa muito fácil e "acabamos falando sobre atos sexuais, funções do corpo humano, métodos anticoncepcionais, prevenção de doenças" ${ }^{33}$ como se as sexualidades estivessem resumidas a uma "materialidade biológica, desconsiderando o papel e os efeitos das construções culturais". ${ }^{24}$ Para Jeffrey Weeks, a sexualidade "é uma experiência histórica e pessoal", ${ }^{25}$ por isso não devemos tentar entendêla apenas sob os aspectos naturais. Nesse sentido, incorporada às práticas de ensino, a seção Sexo da revista Capricho pode ser pensada como um artefato que promove a inserção da temática sexualidade no âmbito escolar a partir de uma perspectiva que considera a sexualidade como uma produção histórica e cultural advinda das experiências dos sujeitos e não apenas como algo simplesmente relacionado a uma materialidade biológica, mas também a prazeres e sentimentos.

\section{Tecendo algumas possibilidades de abordagem: a seção Sexo em destaque}

A seção Sexo, assim como a revista Capricho, é publicada quinzenalmente e, a cada edição, a coluna apresenta um assunto diferente relacionado à temática sexualidade. Foram analisadas 27 seções, no período de agosto de 2008 a agosto de 2009, nas quais os seguintes aspectos foram considerados: os temas das discussões, as dicas e os comentários que compõem a coluna e seus respectivos autores. O quadro a seguir apresenta algumas possibilidades de abordagem que foram pensadas a partir das análises das seções.

\footnotetext{
${ }^{22}$ Guacira Lopes LOURO, 2007, p. 43-44.

${ }^{23}$ Paula Regina Costa RIBEIRO, 2002, p. 57.

${ }^{24}$ RIBEIRO, 2002, p. 18.

${ }^{25}$ Jeffrey WEEKS, 1993, p. 21.
} 


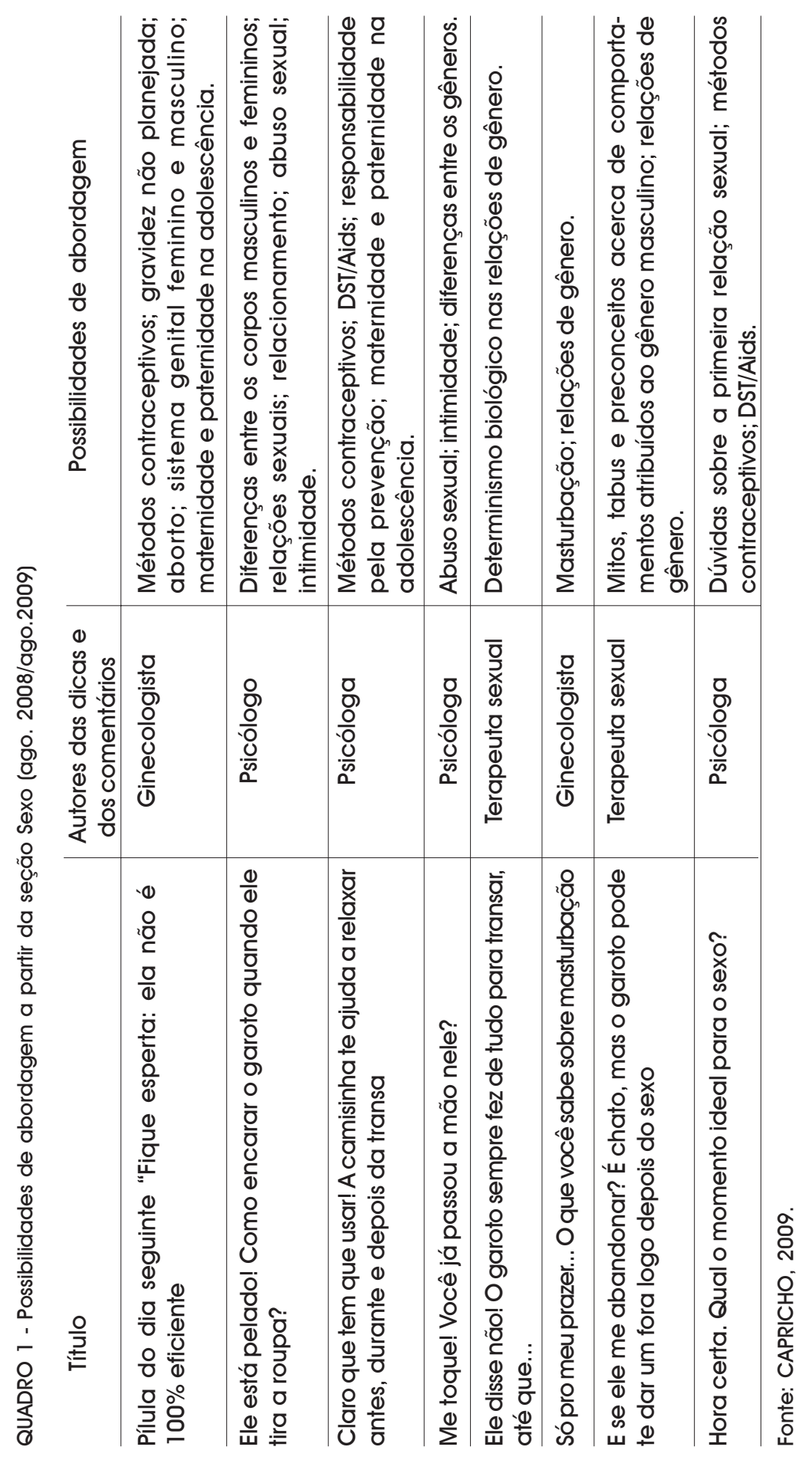

Estudos Feministas, Florianópolis, 19(2): 521-533, maio-agosto/2011 527 
As possibilidades de abordagem que propomos na relação anterior sugerem pensar numa educação para a sexualidade ${ }^{26}$ para além do currículo escolar, uma educação engendrada em um contexto sociocultural. Tomaz Tadeu da Silva ${ }^{27}$ propõe repensar qual conhecimento deve ser ensinado, "o que eles ou elas querem saber? Qual conhecimento ou saber é considerado importante ou válido ou essencial para merecer ser considerado parte do currículo?". ${ }^{28}$ Talvez o primeiro passo para responder a essas questões seja pensarmos no currículo não como o único documento-base do processo de ensino-aprendizagem e muito menos contemplar seus conteúdos como os únicos a serem trabalhados no contexto escolar. Nesse sentido, a revista Capricho funciona como um importante artefato cultural que possibilita a inserção de outras temáticas e discussões não contempladas no currículo escolar, bem como aproxima os conteúdos a serem trabalhados às experiências dos/as alunos/as.

Tradicionalmente, as escolas têm se utilizado de alguns artefatos culturais legitimados pelo currículo escolar, como livros didáticos, palestras, cartazes, PCN, manuais, guias de educação sexual, para problematizar os conhecimentos acerca da sexualidade. Entretanto, consideramos que outros artefatos podem ser utilizados no espaço escolar para discutir essas temáticas como, por exemplo, filmes, livros paradidáticos, programas de televisão, propagandas, internet - Orkut, blogs, sites, entre outros - e revistas em geral. Neste estudo, destacamos como um importante artefato para uma educação para a sexualidade as revistas para adolescentes.

A partir da seção analisada, foi possível perceber que os temas abordados, além de possibilitarem a discussão de questões como sistemas genitais, métodos contraceptivos, Aids e DST, que já estão presentes nos currículos escolares, também permitiram discutir a sexualidade como uma construção cultural e social que, ao correlacionar comportamentos, linguagens, representações, crenças, identidades, posturas, inscreve tais constructos no corpo, através de estratégias de poder/saber sobre os sexos. Dessa forma, percebemos que os conteúdos da seção Sexo da revista Capricho indicam algumas possibilidades de pensarmos a sexualidade na escola para além de uma ciência sexual - scientia sexualis.

Segundo Foucault, a ars erotica e a scientia sexualis caracterizam-se como grandes procedimentos para produzir a verdade sobre o sexo. O que as diferenciam é que, na primeira - própria das sociedades orientais como Japão, Roma, China, Índia e as nações árabe-muçulmanas -, se extraía a verdade "do próprio prazer" ${ }^{29}$ Considerava-se o prazer, sem vínculos a prescrições morais, proibições ou permissões, ou seja, o saber da arte erótica é atribuído à própria prática sexual. No entanto, na scientia sexualis, diferente da ars erotica, na qual o saber sobre o prazer "deve permanecer secreto", ${ }^{30}$ o sexo aparece como objeto de saber que deve ser confessado através de procedimentos (exames, interrogatórios, observações, entrevistas) que incitam a falar sobre o sexo e assim produzir verdades e discursos científicos acerca dele. Dessa forma, desde o século XIX, nossa sociedade fala sobre a sexualidade a partir da ciência sexual, isto é, utiliza o discurso científico para falar sobre a sexualidade dos sujeitos.

\footnotetext{
${ }^{26}$ Segundo Constantina XAVIER FILHA, 2009, p. 96-97, "como prática que visa a refletir, problematizar desconstruir discursos considerados como 'únicas' possibilidades, evidenciando que os discursos são construções culturais e que suas formas de enunciação são capazes de produção de subjetividades. A dúvida da certeza, a transitoriedade das convicções, as possibilidades de colocar-se em xeque diante do novo [...] são algumas das possibilidades de uma perspectiva da 'educação para a sexualidade'”.

${ }^{27}$ SILVA, 2009

${ }^{28}$ SILVA, 2009, p. 14-15.

${ }^{29}$ FOUCAULT, 2007, p. 65.

${ }^{30}$ FOUCAULT, 2007 , p. 66.
}

528 Estudos Feministas, Florianópolis, 19(2): 521-533, maio-agosto/2011 
Segundo Ribeiro, nosso sexo é administrado pela scientia sexualis,

[...] na escola, a ênfase é tratar a sexualidade por essa via, ou seja, pela aquisição de conhecimentos científicos (categorizações e descrições) dos sistemas reprodutores e genitalidade - atributo biológico compartilhado por todos, independentemente de sua história e cultura. $^{31}$

Nesse sentido, tanto a escola quanto a mídia tendem a (re)produzir discursos acerca da sexualidade respaldados em discursos cientificistas, que tomam como referência uma materialidade biologicamente natural. Dessa forma, é possível perceber por que a sociedade contemporânea é constituída principalmente por uma scientia sexualis e não por uma ars erotica, pois mesmo na seção Sexo, a qual possibilita múltiplas abordagens acerca da sexualidade, ao analisarmos os autores das dicas e dos comentários, observase que os saberes e conhecimentos acerca da temática sexualidade estão engendrados numa ciência sexual, pois as vozes, às quais foram conferidas a autoridade e a capacidade de falar a respeito de tal assunto, são/estão atribuídas às ciências - psicólogos/as, professores/as de psicologia, sexólogos/as, terapeutas, terapeutas sexuais, educadores/as sexuais e ginecologistas. Dessa forma, respaldada pelo conhecimento científico, a Revista assegura veridicidade e legitimidade ao conteúdo publicado.

Ao pensar a sexualidade apenas pelo viés de uma ciência sexual, tende-se também, devido às atribuições biológicas supostamente entendidas como compartilhadas por todos, a vincular a natureza biológica "às características anatômicas - internas e externas - dos corpos, fixando nessas características a sexualidade e as diferenças atribuídas aos homens e mulheres", ${ }^{32}$ naturalizando, assim, "diferenças atribuídas nas culturas aos homens e às mulheres (identidades de gênero, identidades sexuais, posições sociais...)." ${ }^{33}$

Nesse processo de naturalização, atrelados ao discurso biológico, outros discursos são produzidos como, por exemplo, o discurso da família-reprodução, em que a heterossexualidade é dada como norma. Relacionando a sexualidade à procriação e consecutivamente à copulação, justificam-se as relações sexuais e a representação de um modelo familiar formado por um casal heterossexual e seus filhos. ${ }^{34}$

Assim, quando os saberes produzidos acerca da sexualidade estão atrelados ao discurso reprodutivo, efetiva-se a relação heterossexual como privilegiada. Nos títulos da seção Sexo, por exemplo, é possível identificar a heterossexualidade como a única forma possível de relacionamento sexual: Ele está pelado! Como encarar o garoto quando ele tira a roupa? Me toque! Você já passou a mão nele? Ele disse não! O garoto sempre fez de tudo para transar, até que... O outro, com quem a leitora se relaciona, é sempre representado pelo gênero masculino.

Nesse contexto, as análises realizadas a partir da observação da tabela apresentada supõem que a revista Capricho, como artefato cultural na sala de aula, possibilita discutir a sexualidade não apenas pelo viés de uma scientia sexualis, mas também como uma produção cultural e histórica que se constitui a partir das nossas experiências, das formas como vivemos nossos prazeres, nossos desejos.

Portanto, ao oportunizar que discussões acerca das diferenças e relações de gêneros, das múltiplas formas de relacionamentos, das relações sexuais além de finalidades reprodutivas, da maternidade e paternidade na adolescência, de abuso sexual, de

${ }^{31}$ RIBEIRO, 2006, p. 5.

32 RIBEIRO, 2006, p. 5.

${ }^{33}$ RIBEIRO, 2006, p. 15

${ }^{34}$ RIBEIRO, 2002, p. 63. 
intimidade, de masturbação, entre outras, sejam inseridas na sala de aula, possibilita-se uma aprendizagem acerca da sexualidade para além de uma ciência sexual puramente biológica. Nesse sentido, desloca-se o entendimento de uma educação para a sexualidade, fundamentada apenas em órgãos, hormônios e doenças que devem ser prevenidas, para uma educação na qual os/as estudantes se reconheçam como sujeitos de suas sexualidades, e isso vai além de determinações biologicistas que reduzem a sexualidade a normas - relações heterossexuais, por exemplo - e a controles comportamentais - como "Cuide-se", "Use camisinha". Isso implica reconhecer os sujeitos, a quem estamos "educando sexualmente", não como sujeitos universais, mas que individualmente vivem suas sexualidades no sentido amplo de suas existências, ou seja, hormônios, órgãos, corpos, prazeres, anseios, desejos, comportamentos, contexto sociocultural, elementos que atuam de forma integrada na constituição da sexualidade.

\section{Entre o entrelaçar e o tecer dos fios, algumas considerações produzidas}

Partindo do objetivo de discutir a revista Capricho - seção Sexo - como um artefato pedagógico na sala de aula, que possibilita outras abordagens acerca da temática sexualidade que não apenas as contempladas nos currículos escolares, neste trabalho, buscou-se pensar a produção dos processos pedagógicos de aprendizagem como uma rede formada a partir do intercâmbio entre teias pedagógicas, ou seja, as instâncias pedagógicas - PCN, livros didáticos, revistas e outros artefatos culturais - são teias estruturalmente formadas por fios providos de saberes e conhecimentos que foram produzidos num contexto de determinada cultura. Sendo assim, o entrelaçamento desses fios, esses saberes e conhecimentos podem ser articulados, exercendo, assim, o ofício de tecer teias e de se formarem redes, isto é, produzir pedagogias de aprendizagem. A partir da perspectiva dos Estudos Culturais e do entendimento de cultura, foi possível pensarmos em práticas e artefatos culturais como produtores de significados e constituintes de pedagogias. Nesse sentido, ao longo do texto, discutimos a importância de pensar o currículo para além das escolas, ${ }^{35}$ pois as instituições de ensino já não são os únicos espaços privilegiados nos quais operam as pedagogias. Para Ruth Sabat, atualmente, "torna-se imprescindível voltar à atenção para outros espaços que estão funcionando como produtores de conhecimentos e saberes, e a mídia é apenas um desses exemplos". ${ }^{36}$

Assim, a revista Capricho também tem um currículo, "sem ter o objetivo explícito de ensinar, entretanto, é óbvio que elas ensinam alguma coisa". ${ }^{37}$ Dessa forma, utilizar esse artefato como uma ferramenta pedagógica de ensino oportuniza a inserção e a problematização da temática sexualidade com outros entendimentos que não apenas o da scientia sexualis.

Dessa forma, ao apontar a revista Capricho como uma pedagogia cultural que produz e divulga significados acerca da temática sexualidade, entende-se que esse artefato opera não apenas como fonte de informação ou entretenimento, mas como uma importante ferramenta no ensino, propiciando a abordagem de assuntos como diferenças entre os corpos e os gêneros masculinos e femininos, cuidados com o corpo, gravidez não planejada, relacionamentos, DST/Aids, métodos contraceptivos, abuso sexual, relações sexuais, aborto, maternidade e paternidade na adolescência, intimidade, desejos, prazeres

${ }^{35}$ Da perspectiva da teoria curricular, poderíamos dizer que as instituições e as instâncias culturais mais amplas também têm um currículo (SILVA, 2009).

${ }^{36}$ Ruth SABAT, 2001, p. 9.

${ }^{37}$ SILVA, 2009, p. 140. 
e outros, problematizando diferentes representações e significados atribuídos à sexualidade que circulam em nossa sociedade.

Ao entendermos que nós, profissionais da educação, produzimos o currículo escolar, torna-se possível, segundo Silva, ${ }^{38}$ "desviá-los, refratá-los, subvertê-los, parodiá-los, carnavalizá-los, contestá-los". Nessa direção, a seção Sexo da revista Capricho pode atuar como um importante artefato pedagógico, no sentido de discutir a sexualidade não apenas pelo viés de uma ciência sexual, como vem sendo apresentado nos livros didáticos, nos PCN e também em outros artefatos culturais, mas também como uma produção que se dá a partir de comportamentos, atitudes, prazeres, desejos, valores, que, ao serem inscritos nos corpos, definem a sexualidade e as próprias pessoas.

A seção Sexo, como artefato cultural, além de produzir e divulgar saberes, conhecimentos e significados, tem grande circulação entre adolescentes, potencializando a amplitude dos discursos midiáticos que interpelam identidades adolescentes. Para Márcia Figueira, "aqui é possível pensar que a Capricho é, junto a tantas outras, uma instância a constituir identidades adolescentes". ${ }^{39}$

Partindo do entendimento de adolescência como uma construção sociocultural e histórica repleta de significados, é possível dizer "que a adolescência não é uma etapa 'natural' da vida", ${ }^{40}$ mas sim uma criação humana que, ao descrevê-la, produz significados "que são referências para a constituição dos sujeitos adolescentes". ${ }^{41}$

Para Fischer, ${ }^{42}$ a partir da invenção do termo "adolescência", a mídia, junto às campanhas publicitárias e ao marketing, criam e divulgam a denominação teen para o público determinado como adolescente. Dessa forma, o modo de ser adolescente "tornase alvo dos discursos produzidos e veiculados no cinema, na televisão, nas revistas e jornais, nos corredores de shopping centers ou nos bares e pontos de festa". ${ }^{43}$

Na especificidade deste trabalho, na seção Sexo da revista Capricho, observamos que os discursos produzidos acerca da sexualidade são colocados às leitoras como discursos de orientação e informação que ensinam saberes, atitudes, sensações e formas de se viver a sexualidade adolescente. Assim, a partir de suas pedagogias, a revista Capricho educa para formas únicas de sexualidade.

Dessa forma, as possibilidades de abordagem, a partir dos títulos de algumas edições da seção Sexo, possibilitam problematizar conhecimentos e cuidados com os corpos, as diferenças físicas e sociais estabelecidas entre gêneros, nas identidades sexuais, na aparência, nos modos de agir, nos modos de sentir o prazer, nos relacionamentos, nas intimidades e em outras questões, talvez aqui não contempladas e que levarão a entendimentos que permitirão pensar em diferentes formas de viver a sexualidade.

Nesse contexto, para que seja possível (re)pensar e discutir a sexualidade, na tentativa de possibilitar um ensino integrado e contextualizado, percebemos que é preciso articularmos diferentes formas pedagógicas de aprendizagem, não se limitando apenas ao espaço escolar e seus objetos didáticos.

Dessa forma, para que possamos pensar e efetuar de fato um ensino articulado e contextualizado, tanto no âmbito da sexualidade quanto em qualquer outro tema, objetivando a formação de sujeitos, julgamos necessário retornarmos a uma das questões

${ }^{38}$ SILVA, 2008, p. 194.

${ }^{39}$ Márcia Luiza Machado FIGUEIRA, 2003, p. 7

40 QUADRADO, 2008, p. 12.

41 QUADRADO, 2008, p, 12.

42 FISCHER, 1996

${ }^{43}$ FISCHER, 1996, p. 25. 
apontadas por Tomaz Tadeu da Silva, ${ }^{44}$ "o que eles ou elas devem saber?", sem esquecer, conforme nos lembra o autor, que "a pergunta 'o quê' nunca está separada de uma outra importante pergunta: 'o quê eles ou elas devem ser?' ou melhor 'o quê eles ou elas devem se tornar?'”, ou seja, que tipos de teias queremos tecer? Que tipo de seres humanos queremos formar?

Assim, embora ensine formas singulares de viver a sexualidade, a Revista possibilita, a partir da seção Sexo, pensarmos e problematizarmos a sexualidade na sala de aula não apenas a partir de uma materialidade e funções biológicas - órgãos, hormônios, reprodução -, mas compreendê-la como uma produção que se dá culturalmente a partir das experiências das pessoas, correlacionando corpos, prazeres, sensações, linguagens, representações, desejos, identidades, crenças etc.

\section{Referências bibliográficas}

ALTMANN, Helena. "Orientação Sexual nos Parâmetros Curriculares Nacionais". Revista Estudos Feministas. 2001. Disponível em: <http://www.scielo.br/scielo.php?script=sci_arttext\&pid $=$ S0104-026X2001000200014\&lng = pt\&nrm=iso >. Acesso em: 20 abr. 2009.

BRASIL. Secretaria de Educação Fundamental. Parâmetros Curriculares Nacionais: terceiro e quarto ciclos: apresentação dos temas transversais. Brasília: MEC/SEF, 1998.

CAPRICHO. Disponível em: <http://app.arquivo.abril.com.br/texto_integral_abril/ pesquisaConteudo.do>. Acesso em: 22 ago. 2009.

CASTRO, Edgardo. Vocabulário de Foucault: um percurso pelos seus temas, conceitos e autores. Belo Horizonte: Autêntica Editora, 2009.

FIGUEIRA, Márcia Luiza Machado. "A revista Capricho e a construção de representações de feminilidade adolescente". In: CONGRESO IBEROAMERICANO DE HISTORIA DE LA EDUCACIÓN LATINO AMERICANA, 6., 2003, San Luis Potosí. p. 1-14. Disponível em: <http:/ /boletimef.org/biblioteca/2383/Revista-Capricho-e-a-construcao-de-representacoes-defeminilidade >. Acesso em: 12 nov. 2010.

FISCHER, Rosa Maria Bueno. Adolescência em discurso: mídia e produção de subjetividade. 1996. Tese (Doutorado em Educação) - Faculdade de Educação, Universidade Federal do Rio Grande do Sul, Porto Alegre, 1996.

FOUCAULT, Michel. Em defesa da sociedade: curso no Collège de France (1975-1976). São Paulo: Martins Fontes, 2005.

História da sexualidade 1: a vontade de saber. 18. ed. São Paulo: Grall, 2007.

HALL, Stuart. "The Work of Representation." In: (Org.). Representation: Cultural Representations and Signifying Practices. London/Thousand Oaks/New Delhi: Sage/Open University, 1997. p. 1-73.

HISTÓRIA da Capricho. Disponível em: <http://capricho.abril.com.br/clube/historia.shtml> . Acesso em: 2 nov. 2010.

LOURO, Guacira Lopes. "Currículo, gênero e sexualidade: o 'normal', o 'diferente' e o 'excêntrico'”. In:___ (Org). Corpo, gênero e sexualidade: um debate contemporâneo na educação. 3. ed. Petrópolis: Vozes, 2007. p. 41-52.

PUBLIABRIL. Disponível em: <http://www.publicidadeabril.com.br/marcas/capricho/revista/ informacoes-gerais >. Acesso em: 10 fev. 2011.

QUADRADO, Raquel Pereira. Adolescentes: corpos inscritos pelo gênero e pela cultura de consumo. 2006. Dissertação (Mestrado em Educação Ambiental) - Programa de PósGraduação em Educação Ambiental, Universidade Federal do Rio Grande, 2006.

${ }^{44}$ SILVA, 2009, p. 15. 
"A adolescência como construção sócio-cultural e histórica". In: RIBEIRO, Paula Regina Costa; QUADRADO, Raquel Pereira (Org.). Corpos, gêneros e sexualidades: questões possíveis para o currículo escolar. Rio Grande: FURG, 2008. p. 11-15.

RIBEIRO, Paula Regina Costa. Inscrevendo a sexualidade: discursos e práticas de professoras das séries iniciais do Ensino Fundamental. 2002. Tese (Doutorado em Bioquímica) Programa de Pós-Graduação em Bioquímica, Instituto de Ciências Básicas da Saúde, Universidade Federal do Rio Grande do Sul, Porto Alegre, 2002.

"Scientia sexualis \& ars erotica: é possível pensarmos a sexualidade na escola pela via da ars erotica?". In: COLÓQUIO FRANCO-BRASILEIRO DE FILOSOFIA DA EDUCAÇÃO: FOUCAULT 80 ANOS, 3., 2006, Rio de Janeiro. Anais... Rio de Janeiro, 2006. p. 1-16.

SABAT, Ruth. "Pedagogia cultural, gênero e sexualidade". Revista Estudos Feministas, ano 9 , p. 9-21, 2001. Disponível em: <http://www.scielo.br/pdf/ref/v9n1/8601.pdf > . Acesso em: 27 abr. 2009.

SANTOMÉ, Jurjo Torres. "As culturas negadas e silenciadas no currículo". In: SILVA, Tomaz Tadeu da (Org.). Alienígenas na sala de aula. 7. ed. Petrópolis: Vozes, 2008. p. 159-177.

SILVA, Tomaz Tadeu da. O currículo como fetiche: a poética do texto curricular. Belo Horizonte: Autêntica, 2006.

"Currículo e identidade social: territórios contestados". In: (Org.). Alienígenas na sala de aula: uma introdução aos estudos culturais em educação. 7. ed. Petrópolis: Vozes, 2008. p. 190-207.

Documentos de identidade: uma introdução às teorias do currículo. 3. ed. Belo Horizonte: Autêntica, 2009.

WEEKS, Jeffrey. El malestar de la sexualidade: significados, mitos y sexualidades modernas. Madrid: Talasa, 1993.

XAVIER FILHA, Constantina. "Educação para a sexualidade: carregar água na peneira?". In: RIBEIRO, Paula Regina Costa; SILVA, Méri Rosane Silva; GOELLNER, Silvana Vilodre (Org.). Corpo, gênero e sexualidade: composições e desafios para a formação docente. Rio Grande: FURG, 2009. p. 85-103.

[Recebido em 15 de março de 2011 e aceito para publicação em 10 de maio de 2011]

\begin{abstract}
Sexuality in the Classroom: Weaving Learning Experiences from a Pedagogical Artifact

Abstract: In this article, we discuss the section Sexo of Capricho magazine as a cultural artifact. We understand that this artifact consists in a cultural pedagogy which produces and disseminates meanings on the theme of sexuality, operating it not only as a source of information or entertainment, but as a teaching tool that, besides allowing the discussion of issues such as genital systems, contraceptive methods, AIDS and STD, that are already present in the school curriculum and the National Curriculum Parameters (PCN), promotes the inclusion of yearnings, fears, pleasures, behavior, gender, that are not always approached in the curriculum, thereby problematizing different representations and meanings attributed to sexuality in our society.

Key Words: Cultural Artifacts; Sexuality; Sexo Section.
\end{abstract}

